\title{
Interactive comment on "Sources of Particulate Matter in the Athabasca Oil Sands Region: Investigation through a Comparison of Trace Element Measurement Methodologies" by Catherine Phillips-Smith et al.
}

\section{Anonymous Referee \#3}

\section{Received and published: 16 May 2017}

The manuscript by Phillips-Smith et al. investigated sources of PM2.5 in the Athabasca Oil Sands region based on PMF analyses of particulate metals. The metal species were derived from a long-term campaign in which filter-based measurements were conducted at three sites, and also from an intensive campaign in which semi-continuous measurements were performed at one of the long-term sites. Interestingly, PMF results were compared between these two campaigns. The topic of this manuscript is within the scope of the special issue "Atmospheric emissions from oil sands development and their transport, transformation and deposition". However, I cannot support its publication in the current form. As can be seen from my detailed comments given below, my 
major concerns are about the PMF results.

1. Page 3, line 25-28. It is not appropriate to list "modelling", "airborne studies" and "comparison of PM2.5 concentrations" successively in one sentence.

2. Page 4, line 9-13. The authors implied that no source apportionment study had been performed for the oil sands region using metal species of PM2.5. However, it is unclear whether there are any previous source apportionment studies using other PM2.5 components (e.g., water-soluble ions, organic carbon, elemental carbon and etc.). Please clarify.

3. Page 4, line 24-26. No content in the results and discussion section corresponds to the second purpose presented here.

4. Line 29 in Page 4 to line 8 in page 5. This paragraph should be presented much more briefly, since all the descriptions involved here are repeated in the methods section.

5. Page 9, line 6-9. Please provide (representative) scatter plots comparing ICP-MS and ED-XRF measurement results on the same metals.

6. Page 11, line 12-15. It is unclear which PMF profile (i.e., Upgrader Emissions I shown in Figure 2 or 3 ) was used for the comparison to the profile reported by Landis et al. (2012). In addition, it is quite surprising that the regression analysis could show an $r$ value of 1.00 . Does this mean that the two profiles are exactly the same?

7. Page 11, line 29-30. V and $\mathrm{Ni}$ were used to indicate oil combustion. However, as shown in Figure 2, the majority of Ni was attributed to the Mixed Sources factor; on the other hand, negligible $V$ was seen in the Mixed Sources factor. These results mean that the major sources of $\mathrm{V}$ and $\mathrm{Ni}$ are different. Consequently, I don't think it is reliable to attribute the Upgrader Emissions II factor to oil combustion, unless the authors could demonstrate that the $\mathrm{V}$ to $\mathrm{Ni}$ ratio calculated for this factor was comparable to that measured in source emissions from oil combustion.

Printer-friendly version

8. Page 13, line 17. According to Figure 2 and 3, concentrations of Mn and Fe were 
higher in the Haul Road Dust factor compared to the Soil factor.

9. Page 13, section 3.2.5. Figure 3 indicates that biomass burning was the major source of $\mathrm{Cd}$. Moreover, the biomass burning contribution to $\mathrm{Cd}(\sim 80 \%)$ was more significant than its contribution to $\mathrm{K}(\sim 60 \%)$. However, previous source emission studies typically suggest that biomass burning is not a strong source of $\mathrm{Cd}$ (e.g., Schmidl et al., Atmos. Environ., 42, 126-141, 2008 and references therein). The authors are required to provide references to support their discussions here, i.e., biomass burning could be the major source of $\mathrm{Cd}$.

10. Page 14, section 3.2.6. High abundance of Ni observed in the Mixed Sources factor should be discussed.

Interactive comment on Atmos. Chem. Phys. Discuss., doi:10.5194/acp-2016-966, 2017. 